\title{
Communication
}

\section{Engineering cytochrome P450s for enantioselective cyclopropenation of internal alkynes}

\author{
Kai Chen, and Frances H. Arnold
}

J. Am. Chem. Soc., Just Accepted Manuscript • DOI: 10.1021/jacs.0c01313 • Publication Date (Web): 29 Mar 2020

Downloaded from pubs.acs.org on March 30, 2020

\section{Just Accepted}

"Just Accepted" manuscripts have been peer-reviewed and accepted for publication. They are posted online prior to technical editing, formatting for publication and author proofing. The American Chemical Society provides "Just Accepted" as a service to the research community to expedite the dissemination of scientific material as soon as possible after acceptance. "Just Accepted" manuscripts appear in full in PDF format accompanied by an HTML abstract. "Just Accepted" manuscripts have been fully peer reviewed, but should not be considered the official version of record. They are citable by the Digital Object Identifier (DOI®). "Just Accepted" is an optional service offered to authors. Therefore, the "Just Accepted" Web site may not include all articles that will be published in the journal. After a manuscript is technically edited and formatted, it will be removed from the "Just Accepted" Web site and published as an ASAP article. Note that technical editing may introduce minor changes to the manuscript text and/or graphics which could affect content, and all legal disclaimers and ethical guidelines that apply to the journal pertain. ACS cannot be held responsible for errors or consequences arising from the use of information contained in these "Just Accepted" manuscripts. 
Cyclopropenes, with endo-cyclic double bonds inside a threemembered carbocycle, possess high strain energy, which enables activity in different strain-release transformations for constructing a myriad of useful molecular scaffolds. ${ }^{1}$ Carbene transfer to alkynes represents one of the most straightforward approaches to constructing cyclopropenes. ${ }^{1 \mathrm{a}, \mathrm{b}}$ Small-molecule transition metal complexes based on rhodium, iridium, cobalt and others have been shown to catalyze carbene transfer to terminal alkynes to yield enantio-enriched cyclopropenes. ${ }^{2-4}$ However, enantioselective carbene transfer to internal alkynes still remains largely unexplored. Only two systems with chiral gold/silver ${ }^{5}$ or rhodium ${ }^{6}$ (co-)catalysts have been reported to take internal aromatic alkynes for asymmetric cyclopropene synthesis with good stereoselectivities. These systems require precious metal catalysts in relatively high loading together with complicated ligands and have not been shown to work with internal aliphatic alkynes. We wanted to develop an efficient biocatalytic platform that uses earthabundant iron to access internal cyclopropenes.

Cytochromes P450 use an iron-heme complex as their catalytic cofactor in their native oxygenase functions. ${ }^{7}$ Recently, directed evolution has significantly expanded the catalytic repertoire of P450 enzymes and other hemeproteins to include non-natural carbene- and nitrene-transfer reactions, as described by our group and others. ${ }^{8-10} \mathrm{We}$ recently reported an enzymatic platform of engineered cytochrome P450 enzymes for stereoselective carbene addition to terminal alkynes to forge cyclopropenes and bicyclo[1.1.0]butanes (Figure 1). ${ }^{11}$ We hypothesized that P450 enzymes may achieve even more challenging transformations, such as carbene transfer to internal alkynes for cyclopropene construction. The major difficulty for internal alkyne cyclopropenation lies in the severe steric clash between the linear

$\pi$-system and the planar heme cofactor, especially if the reaction involves a concerted carbene-transfer mechanism. ${ }^{12}$ Recent mechanistic studies have shown step-wise carbene-transfer processes or even multiple pathways for the same type of reactions with different engineered hemeproteins. ${ }^{13} \mathrm{We}$ reasoned that proper engineering of the enzyme active site may direct the desired carbene transfer to proceed through a step-wise pathway, thereby circumventing the steric issue.

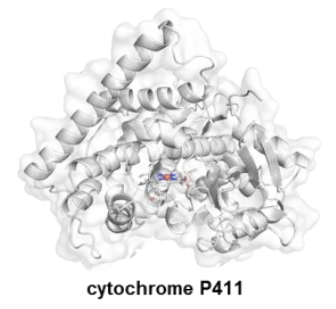

heme protein carbene transferase

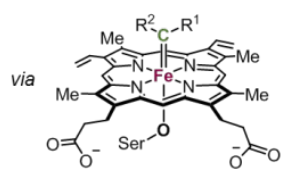

iron-carbene intermediate

P411-catalyzed carbene transfer to terminal alkynes

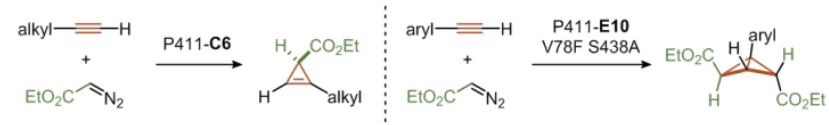

P411-C10 for cyclopropenation of internal alkynes

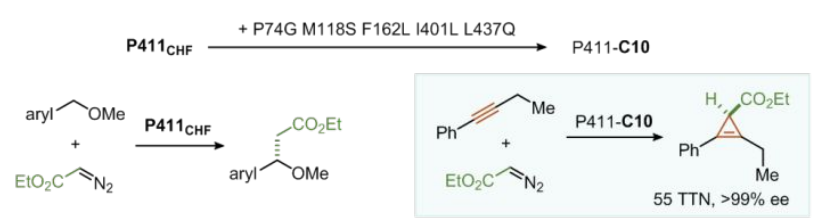

Figure 1. Enzymatic carbene transfer to alkynes for strained carbocycle formation.

We initiated investigation of internal aromatic alkyne cyclopropenation using ethyl diazoacetate (EDA) as the carbene precursor and 1-phenylbutyne (1a) as the model alkyne substrate. Screening various hemeprotein variants based on P450s, P411s (P450 with axial ligating residue mutated to serine), ${ }^{14}$ cytochromes $c$ and globins in the form of whole Escherichia coli (E. coli) cell catalysts identified a P411 variant, P411-C10, that formed the desired internal cyclopropene (Figure 1). P411-C10 belongs to the family of $\mathbf{P 4 1 1}_{\mathbf{C H F}}$ (five amino acid substitutions away), which was evolved for a carbene $\mathrm{C}-\mathrm{H}$ insertion reaction. ${ }^{15}$ Surprisingly, the cyclopropene product synthesized by P411-C10 was determined to be a single enantiomer, which suggests the enzyme scaffold binds the alkyne and directs carbene transfer in a well-defined orientation.

For the model reaction with $\mathbf{1 a}$ as the alkyne donor, $\mathbf{C 1 0}$ in the 
form of the whole-cell catalyst exhibited modest activity, with 55 total turnovers (TTN). Directed evolution targeting active-site residues for site-saturation mutagenesis was performed to enhance the overall catalytic efficiency (Figure 2). Residue 263, located right above the heme cofactor (in the heme domain), was previously found to play an important role in controlling carbene transfer to phenylacetylene using other P411 variants. ${ }^{11}$ To our delight, screening the enzyme library made by site-saturation mutagenesis at residue 263 yielded a tryptophan mutation at this site that improved TTN over 11 fold. Sequential mutagenesis targeting sites in the loop regions led to beneficial mutations Q437I, S72F and L436R and afforded the highly efficient variant WIRF, with 2680 TTN towards the desired cyclopropene formation.

P411 C10-WIRF's scope of internal alkynes bearing different aromatic rings or carbon chains was then evaluated. For the alkyne substrates tested (1) to $\mathbf{1 l}$ ), only cyclopropenes $\mathbf{2 c}, \mathbf{2 d}, \mathbf{2} \mathbf{i}$ and $\mathbf{2} \mathbf{j}$ were synthesized efficiently, and most of the other alkynes with substitutions on the aromatic ring showed poor to moderate reactivities. Thinking that the evolved WIRF variant may have acquired some specificity for the non-substituted aromatic ring or for electron-rich alkynes, we decided to use a less reactive alkyne substrate (compared to $\mathbf{1 a}$ ), $\mathbf{1 b}$, with an electron-deficient parachloro substitution, to further evolve the enzyme (Figure 2). A sitesaturation library targeting residue 332 afforded mutation $\mathrm{S} 332 \mathrm{G}$, which boosted the total turnover by almost 5 fold. We reasoned that the glycine substitution might help make space in the active site to accommodate substrates with substitutions on the aromatic ring. Mutagenesis of residues close to 332 was investigated, and two additional beneficial mutations, G74A and E70K, yielded the final WIRF_GAK variant with 2320 TTN for substrate $\mathbf{1 b}$.

Figure 2. Directed evolution of P411-C10 for internal cyclopropene synthesis. Reaction conditions: $10 \mathrm{mM}$ alkyne, $10 \mathrm{mM}$ EDA, E. coli harboring P411-C10 variants $\left(\mathrm{OD}_{600}=15\right.$ to 60$)$, D-glucose $(25 \mathrm{mM})$, M9-N buffer/EtOH (19:1), anaerobic, 6 h. Product formation was quantified by gas chromatography (GC) and TTNs were determined based on P411 protein concentration. The heme-domain structure of P411-E10 variant (pdb: 5UCW) was used to guide site-saturation mutagenesis; mutation sites are highlighted. See SI for details.

We revisited the substrate scope of this biocatalytic platform using the whole lineage of cyclopropene-forming enzyme variants (from C10 to WIRF and then to WIRF_GAK) (Figure 3). The WIRF variant turned out to be efficient for non-substituted or ortho-substituted aromatic alkynes (1a, 1c and 1d), catalyzing the desired cyclopropene synthesis with 1200 to 2670 total turnovers, while variants from later in the evolution showed impaired activity with these substrates. Although we did not specifically evolve the enzyme for activity on meta-substituted aromatic alkynes, variant WIRF_G exhibited improved efficiency for a meta-methoxyl alkyne substrate (1f), compared to WIRF. For aromatic alkynes bearing para-substitutions or $d i$-substitutions (1b and $\mathbf{1 g}$ to $\mathbf{1 1})$, the final variant WIRF_GAK catalyzes the desired transformations with unprecedentedly high efficiency compared to all previously reported systems for cyclopropene formation. For instance, an electronically-withdrawing trifluoromethyl-substituted alkyne (1g) was well-accepted by the enzymatic system. It is worth noting that all of the internal cyclopropenes produced enzymatically were determined to be single enantiomers $(>99.9 \%$ ee for all), which further supports our hypothesis that the engineered enzymes impose a specific binding orientation of the alkyne substrate in the protein active site, allowing for efficient carbene addition to triple bonds with perfect stereocontrol. 


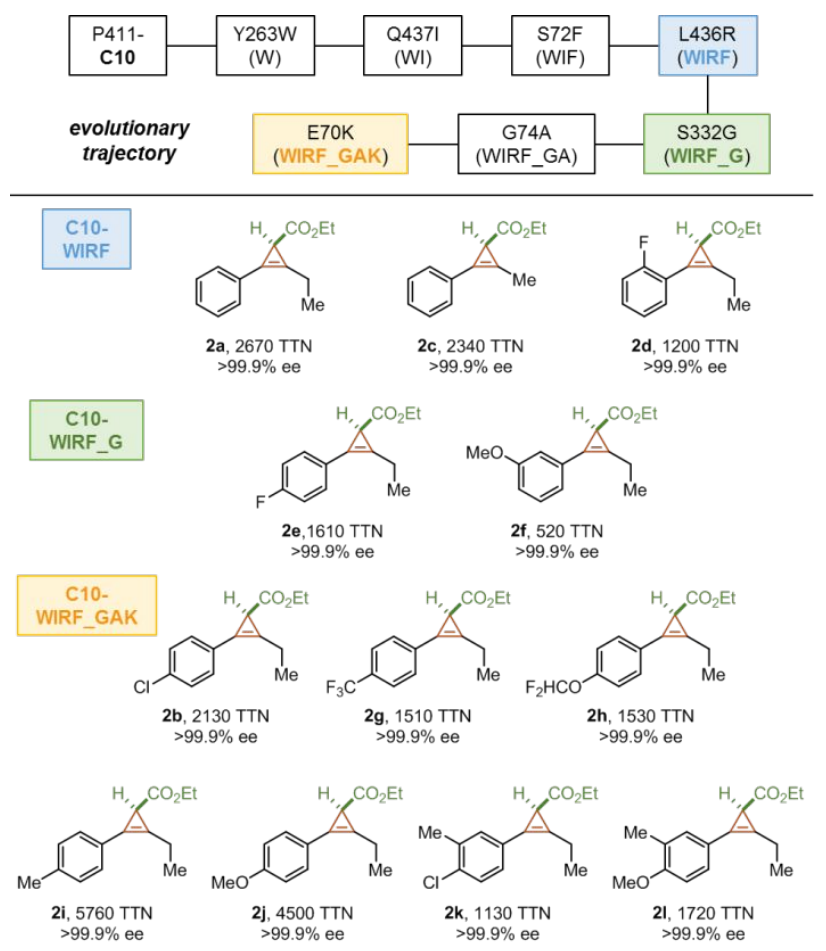

Figure 3. Substrate scope of internal aromatic alkynes for cyclopropene formation. Reactions were performed in quadruplicate under the following conditions: $10 \mathrm{mM}$ alkyne, 10 mM EDA, E. coli harboring P411-C10 variants $\left(\mathrm{OD}_{600}=10\right.$ to 20$)$, D-glucose (25 mM), M9-N buffer/EtOH (19:1), anaerobic, $16 \mathrm{~h}$. Product formation was quantified by gas chromatography (GC) and TTNs were determined based on protein concentration. See SI for details.

To further demonstrate the utility of this highly stereoselective enzymatic platform, we carried out large-scale preparation of internal cyclopropenes (Figure 4). With a simple modification of the reaction conditions using the diazo reagent in excess $(2.4$ equivalents added in three portions), we obtained high isolated yields of the desired cyclopropene products at mmol scale ( $90 \%$ for 2d with variant WIRF, and $87 \%$ for $\mathbf{2 g}$ with variant WIRF GAK). Interestingly, the enzyme turnovers of the large-scale reactions are typically higher than those obtained with analytical-scale ones, indicating that the evolved enzymes in whole cells might still retain (partial) activity after the reactions and the turnovers were limited by consumption of the diazo substrate.

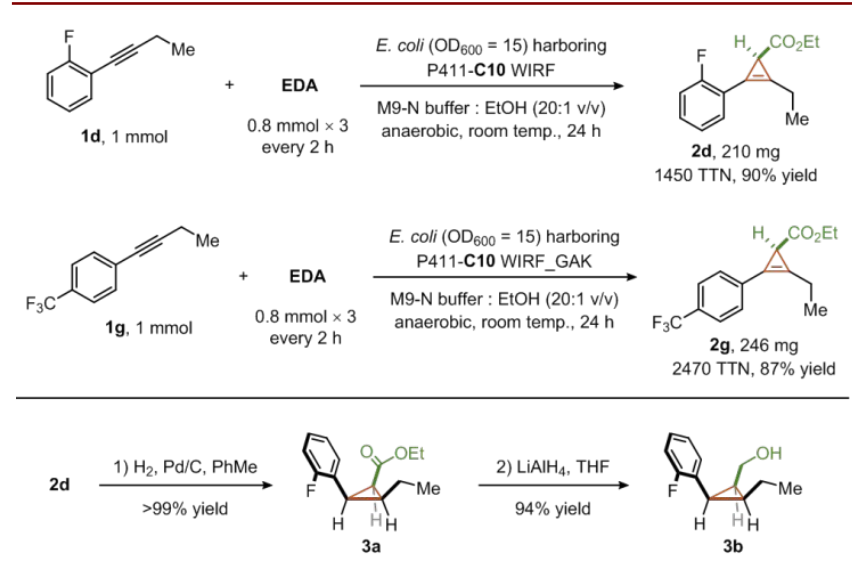

Figure 4. Preparative-scale synthesis of internal cyclopropenes and further derivatization. See SI for details.
Numerous transformations have been developed to furnish diverse molecular structures from versatile cyclopropane building blocks. ${ }^{1,2 b, 2 c, 6,7}$ Here, we also derivatized the enzymaticallysynthesized cyclopropenes by hydrogenation and ester reduction to afford an all-cis cyclopropane product (Figure 4), which is otherwise difficult to prepare due to the cis-stereochemistry of the three substituents on the cyclopropane ring.

Compared to internal aromatic alkynes described above, internal aliphatic alkynes are typically more challenging targets for enantioselective cyclopropene formation in terms of reactivity and selectivity. As the aryl groups on aromatic alkynes can provide a stabilizing effect through the conjugated system in the carbene transfer process, purely aliphatic alkynes without additional intramolecular effects may suffer from a higher energy barrier for carbene transfer. Additionally, alkyl groups at the two ends of the triple bond are less easy to distinguish than the alkyl and aryl groups on aromatic alkynes. Until now, no systems have been reported for enantioselective cyclopropene synthesis with internal aliphatic alkynes. However, we believed that enzymes can accomplish this, as the enzyme active site is a chiral environment that can recognize minor steric differences for chiral induction. ${ }^{16}$

Testing the evolved enzymes for a cyclopropenation reaction with internal aliphatic alkyne $\mathbf{1 m}$ was not fruitful, as only trace activity was observed. However, with the parent enzyme P411-C10 we observed the desired cyclopropene product $\mathbf{2 m}$ (Figure 5) with modest activity (43 TTN). This might be because the whole enzyme lineage was evolved for a set of structurally different aromatic alkynes. Further screening of variants in the $\mathbf{C 1 0}$ family identified a triple mutant of C10, C10_VLC, which catalyzed the formation of internal cyclopropene $\mathbf{2 m}$ with improved activity (64 TTN) and perfect stereocontrol $(>99 \%$ ee). We anticipate that further evolution will lead to more efficient enzymes for internal aliphatic cyclopropene construction, as we have demonstrated for aromatic alkynes.

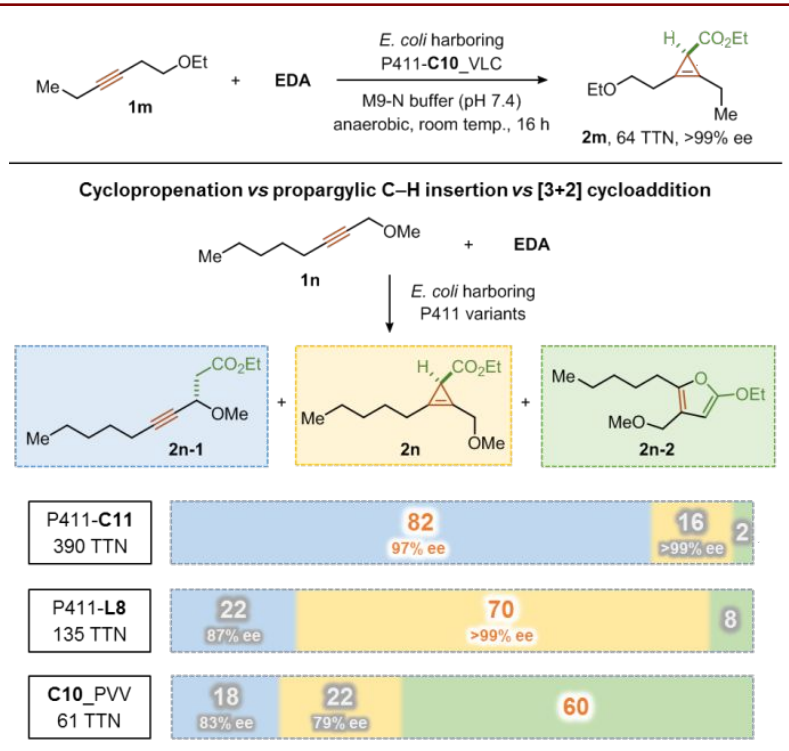

Figure 5. Cyclopropenation of internal aliphatic alkynes and chemoselectivity study with substrate 1n. Reactions were performed in quadruplicate under the following conditions: $10 \mathrm{mM}$ alkyne, $10 \mathrm{mM}$ EDA, E. coli harboring P411 variants $\left(\mathrm{OD}_{600}=15\right.$ to 20), D-glucose (25 mM), M9-N buffer/EtOH (19:1), anaerobic, 16 h. C10_VLC: C10 T327V Q437L S332C; C11: C10 G74T S118M L162F L401I Q437L; L8: C10 A87P A264S E267D T327P S332A Q437L; C10 PVV: C10 Q437P T327V A87V. See SI for details. 
As the parent P411-C10 enzyme was initially engineered for a carbene $\mathrm{C}-\mathrm{H}$ insertion reaction, we took a deeper look at the chemoselectivity between cyclopropenation and $\mathrm{C}-\mathrm{H}$ insertion. ${ }^{15}$ Internal alkyne substrate $\mathbf{1 n}$, bearing a propargylic ether group, was found to mainly undergo a carbene insertion reaction into the propargylic $\mathrm{C}-\mathrm{H}$ bond with high enantioselectivity with catalyst P411 $_{\text {CHF }}$; a cyclopropene product was also detected as a minor product (see SI for details). However, P411-C10 reversed the chemoselectivity to favor the cyclopropene $\mathbf{2 n}$ as the major product; and a third product observed in low proportion in this latter reaction was confirmed to be a furan derivative, $\mathbf{2 n - 2}$, which may be generated through a [3+2]-cycloaddition. ${ }^{11,17}$ After intensive screening of variants in the families of $\mathbf{P 4 1 1}_{\mathbf{C H F}}$ and P411-C10, we discovered two related variants, P411-C11 and P411-L8, which could catalyze the $\mathrm{C}-\mathrm{H}$ insertion reaction and the cyclopropenation reaction with even higher activity and selectivity (compared to P411 $_{\text {CHF }}$ and P411-C10, respectively), as shown in Figure 5. And a C10 triple mutant, C10_PVV, was found to flip the chemoselectivity to favor formation of the furan product. These variants are closely related, differing by only a few amino acid substitutions, but gave very different chemoselectivities without any specific enzyme evolution. These results, together with our

\section{ASSOCIATED CONTENT}

\section{Supporting Information}

Experimental details, and spectral data for all new compounds. This material is available free of charge via the Internet at http://pubs.acs.org.

\section{AUTHOR INFORMATION}

\section{Corresponding Author \\ frances@cheme.caltech.edu (F.H.A.)}

\section{ORCID}

Kai Chen: 0000-0002-3325-3536

Frances H. Arnold: 0000-0002-4027-364X

\section{Notes}

The authors declare no competing financial interests.

\section{ACKNOWLEDGMENT}

This work was supported by NSF Division of Molecular and Cellular Biosciences grant MCB-1513007, US Army Research Office Institute for Collaborative Biotechnologies cooperative agreement W911NF-19-2-0026, and US Army Research Office Institute for Collaborative Biotechnologies contract W911NF-19D-0001. K.C. thanks the Resnick Sustainability Institute at Caltech for fellowship support. We thank R. K. Zhang, N. P. Dunham, D. J. Wackelin, Y. Yang and M. Garcia-Borràs for helpful discussions and comments.

\section{REFERENCES AND NOTES}

(1) Reviews with topics on cyclopropenes: a) Marek, I.; Simaan, S.; Masarwa, A. Enantiomerically enriched cyclopropene derivatives: Versatile building blocks in asymmetric synthesis. Angew. Chem., Int. Ed. 2007, 46, 7364-7376. b) Zhu, Z.-B.; Wei, Y.; Shi, M. Recent developments of cyclopropene chemistry. Chem. Soc. Rev. 2011, 40, 5534-5563. c) Rubin, M.; Rubina, M.; Gevorgyan, V. Transition metal chemistry of cyclopropenes and cyclopropanes. Chem. Rev. 2007, 107, 3117-3179. d) Archambeau, A.; Miege, F.; Meyer, C.; Cossy, J. Intramolecular cyclopropanation and $\mathrm{C}-\mathrm{H}$ insertion reactions with metal carbenoids generated from cyclopropenes. Acc. Chem. Res. 2015, 21, 1021-1031. e) Deng, Y; Doyle, M. P. Versatile donor-acceptor cyclopropenes in metal carbene transformations. Isr. J. Chem. 2016, 56, 399-408. previous demonstration of enzyme-controlled reaction selectivity between $\mathrm{C}-\mathrm{H}$ insertion and cyclopropanation, ${ }^{18}$ highlight how enzyme catalysis can solve chemoselectivity problems in synthetic methodology.

In conclusion, we have developed a versatile biocatalytic platform based on engineered cytochrome P411 enzymes that offers access to an array of structurally diverse internal cyclopropenes through carbene transfer to internal alkynes. This biocatalytic system was evolved rapidly to take internal aromatic alkynes as substrates and furnish the desired cyclopropenes with unprecedentedly high stereoselectivities ( $>99.9 \%$ ee for all). This enzymatic platform is also readily scalable for the production of cyclopropenes in preparative quantities, with even higher efficiencies compared to the analytical-scale reactions. Enantioselective cyclopropenation of internal aliphatic alkynes was also shown to be possible. The versatility and tunability of these biocatalysts has been demonstrated, with chemoselectivity that can be switched among cyclopropenation, carbene $\mathrm{C}-\mathrm{H}$ insertion and $[3+2]$ cycloaddition. Ongoing studies with this family of P411-C10 variants will help to define the catalytic potential of C10 as a highly promiscuous carbene transferase for non-native transformations.

(2) a) Protopopova, M. N.; Doyle, M. P.; Müller, P.; Ene, D. High enantioselectivity for intermolecular cyclopropenation of alkynes by diazo esters catalyzed by chiral dirhodium(II) carboxamides. J. Am. Chem. Soc. 1992, 114, 2755-2757. b) Doyle, M. P.; Protopopova, M.; Müller, P.; Ene, D.; Shapiro, E. A. Effective uses of dirhodium(II) tetrakis[methyl 2oxopyrrolidine-5( $R$ or $S)$-carboxylate] for highly enantioselective intermolecular cyclopropenation reactions. J. Am. Chem. Soc. 1994, 116, 8492-8498. c) Briones, J. F.; Hansen, J.; Hardcastle, K. I.; Autschbach, J.; Davies, H. M. L. Highly enantioselective $\mathrm{Rh}_{2}(S \text {-DOSP })_{4}$-catalyzed cyclopropenation of alkynes with styryldiazoacetates. J. Am. Chem. Soc. 2010, 132, 17211-17215. d) Goto, T.; Takeda, K.; Shimada, N.; Nambu, H.; Anada, M.; Shiroo, M.; Ando, K.; Hashimoto, S. Highly enantioselective cyclopropenation reaction of 1 -alkynes with $\alpha$-alkyl- $\alpha$ diazoesters catalyzed by dirhodium(II) carboxylates. Angew. Chem., Int. Ed. 2011, 50, 6803-6808. e) Davies, H. M. L.; Lee, G. H. Dirhodium(II) tetra $(N$-(dodecylbenzenesulfonyl)prolinate) catalyzed enantioselective cyclopropenation of alkynes. Org. Lett. 2004, 6, 1233-1236. f) Lindsay, V. N. G.; Fiset, D.; Gritsch, P. J.; Azzi, S.; Charette, A. B. Stereoselective $\mathrm{Rh}_{2}(S \text {-IBAZ })_{4}$-catalyzed cyclopropanation of alkenes, alkynes, and allenes: Asymmetric synthesis of diacceptor cyclopropylphosphonates and alkylidenecyclopropanes. J. Am. Chem. Soc. 2013, 135, 1463-1470.

(3) Uehara, M.; Suematsu, H.; Yasotumi, Y.; Katsuki, T. Enantioenriched synthesis of cyclopropenes with a quaternary stereocenter, versatile building blocks. J. Am. Chem. Soc. 2011, 133, 170-171.

(4) Cui, X.; Xu, X.; Lu, H.; Zhu, S.; Wojtas, L.; Zhang, X. P. Enantioselective cyclopropenation of alkynes with acceptor/acceptorsubstituted diazo reagents via $\mathrm{Co}$ (II)-based metalloradical catalysis. J. Am. Chem. Soc. 2011, 133, 3304-3307.

(5) Briones, J. F.; Davies, H. M. L. Gold(I)-catalyzed asymmetric cyclopropenation of internal alkynes. J. Am. Chem. Soc. 2012, 134, 11916 11919

(6) a) A recent example of Rh-catalyzed internal alkyne cyclopropenation during the preparation of this manuscript: Zhang, Z.-Q.; Zheng, M.-M.; Xue, X.-S.; Marek, I.; Zhang, F.-G.; Ma, J.-A. Catalytic enantioselective cyclopropenation of internal alkynes: Access to difluoromethylated three-membered carbocycles. Angew. Chem., Int. Ed. 2019, 58, 18191-18196. b) See ref 2a for preliminary results on the rhodium-catalyzed asymmetric cyclopropenation of internal alkynes in poor enantioselectivity.

(7) a) Ortiz de Montellano, P. R. ed., Cytochrome P450: structure, mechanism, and biochemistry (Springer International Publishing: Cham, 2015). b) Poulos, T. L. Heme enzyme structure and function. Chem. Rev. 2014, 114, 3919-3962.

(8) Reviews and book chapter covering carbene and nitrene chemistries by P450: a) Brandenberg, O. F.; Fasan, R.; Arnold, F. H. Exploiting and engineering hemoproteins for abiological carbene and nitrene transfer reactions. Curr. Opin. Biotechnol. 2017, 47, 102-111. b) Prier, C. K.; Arnold, F. H. Chemomimetic biocatalysis: Exploiting the synthetic potential of cofactor-dependent enzymes to create new catalysts. $J$. Am. 
Chem. Soc. 2015, 137, 13992-14006. c) Zhang, R. K.; Romney, D. K.; Kan, S. B. J.; Arnold, F. H. Chapter 5 in Dieguez, M.; Bäckvall, J.-E.; Pamies, O. eds, Artificial Metalloenzymes and MetalloDNAzymes in Catalysis. From Design to Applications (Wiley-VCH, Weinheim, 2018). d) Chen, K.; Arnold, F. H. Engineering new catalytic activities in enzymes. Nat. Catal. 2020, 3, 103-113. e) Leveson-Gower, R. B.; Mayer, C.; Roelfes, G. The importance of catalytic promiscuity for enzyme design and evolution. Nat. Rev. Chem. 2019, 3, 687-705.

(9) Examples of hemeprotein-catalyzed carbene chemistries: a) Coelho, P. S.; Brustad, E. M.; Kannan, A.; Arnold, F. H. Olefin cyclopropanation via carbene transfer catalyzed by engineered cytochrome P450 enzymes. Science 2013, 339, 307-310. b) Wang, Z. J.; Renata, H.; Peck, N. E.; Farwell, C. C.; Coelho, P. S.; Arnold, F. H. Improved cyclopropanation activity of histidine-ligated cytochrome $\mathrm{P} 450$ enables the enantioselective formal synthesis of levomilnacipran. Angew. Chem., Int. Ed. 2014, 53, 6810-6813. c) Bordeaux, M.; Tyagi, V.; Fasan, R. Highly diastereoselective and enantioselective olefin cyclopropanation using engineered myoglobin-based catalysts. Angew. Chem., Int. Ed. 2015, 54, 1744-1748. d) Chen, K.; Zhang, S.-Q.; Brandenberg, O. F.; Hong, X.; Arnold, F. H. Alternate heme ligation steers activity and selectivity in engineered cytochrome P450-catalyzed carbene transfer reactions. J. Am. Chem. Soc. 2018, 140, 16402-16407. e) Wang, Z. J.; Peck, N. E.; Renata, H.; Arnold, F. H. Cytochrome P450-catalyzed insertion of carbenoids into N-H bonds. Chem. Sci. 2014, 5, 598-601. f) Tyagi, V.; Bonn, R.B.; Fasan, R. Intermolecular carbene $\mathrm{S}-\mathrm{H}$ insertion catalysed by engineered myoglobin-based catalysts. Chem. Sci. 2015, 6, 2488-2494. g) Kan, S. B. J.; Lewis, R. D.; Chen, K.; Arnold, F. H. Directed evolution of cytochrome $\mathrm{c}$ for carbon-silicon bond formation: Bringing silicon to life. Science $\mathbf{2 0 1 6}$ 354, 1048-1051. h) Kan, S. B. J.; Huang, X.; Gumulya, Y.; Chen, K.; Arnold, F. H. Genetically programmed chiral organoborane synthesis. Nature 2017, 552, 132-136.

(10) Examples of hemeprotein-catalyzed nitrene chemistries: a) McIntosh, J. A.; Coelho, P. S.; Farwell, C. C.; Wang, Z. J.; Lewis, J. C.; Brown, T. R.; Arnold, F. H. Enantioselective intramolecular C-H amination catalyzed by engineered cytochrome $\mathrm{P} 450$ enzymes in vitro and in vivo. Angew. Chem., Int. Ed. 2013, 52, 9309-9312. b) Hyster, T. K.; Farwell, C. C.; Buller, A. R.; McIntosh, J. A.; Arnold, F. H. Enzyme-controlled nitrogen-atom transfer enables regiodivergent $\mathrm{C}-\mathrm{H}$ amination. $J$. Am. Chem Soc. 2014, 136, 15505-15508. c) Singh, R.; Kolev, J. N.; Sutera, P. A.; Fasan, R. Enzymatic C $\left(s p^{3}\right)-\mathrm{H}$ amination: P450-catalyzed conversion of carbonazidates into oxazolidinones. ACS Catal. 2015, 5, 1685-1691. d)
Prier, C. K.; Zhang, R. K.; Buller, A. R.; Brinkmann-Chen, S.; Arnold, F. $\mathrm{H}$. Enantioselective, intermolecular benzylic $\mathrm{C}-\mathrm{H}$ amination catalysed by an engineered iron-haem enzyme. Nat. Chem. 2017, 9, 629-634. e) Yang, Y.; Cho, I.; Qi, X.; Liu, P.; Arnold, F. H. An enzymatic platform for the asymmetric amination of primary, secondary and tertiary $\mathrm{C}\left(s p^{3}\right)-\mathrm{H}$ bonds. Nat. Chem. 2019, 11, 987-993.

(11) Chen, K.; Huang, X.; Kan, S. B. J.; Zhang, R. K.; Arnold, F. H. Enzymatic construction of highly strained carbocycles. Science 2018, 360, $71-75$.

(12) A similar rationalization in iron-porphyrin-catalyzed internal alkene cyclopropanation: Wolf, J. R.; Hamaker, C. G.; Djukic, J.-P.; Kodadek, T.; Woo, L. K. Shape and stereoselective cyclopropanation of alkenes catalyzed by iron porphyrins. J. Am. Chem. Soc. 1995, 117, 36, 9194-9199.

(13) Mechanistic studies on hemeprotein catalyzed carbene-transfer reactions: a) Zhang, Y. Computational investigations of heme carbenes and heme carbene transfer reactions. Chem. Eur. J. 2019, 25, 13231-13247. b) Sharon, D. A.; Mallick, D.; Wang, B.; Shaik, S. Computation sheds insight into iron porphyrin carbenes' electronic structure, formation, and $\mathrm{N}-\mathrm{H}$ insertion reactivity. J. Am. Chem. Soc. 2016, 138, 9597-9610. c) Wei, Y.; Tinoco, A.; Steck, V.; Fasan, R.; Zhang, Y. Cyclopropanations via heme carbenes: Basic mechanism and effects of carbene substituent, protein axial ligand, and porphyrin substitution. J. Am. Chem. Soc. 2018, 140, 1649-1662. d) Carminati, D; Fasan, R. Stereoselective cyclopropanation of electron-deficient olefins with a cofactor redesigned carbene transferase featuring radical reactivity. ACS Catal. 2019, 9, 9683-9697. e) ref 10d.

(14) Coelho, P. S.; Wang, Z. J.; Ener, M. E.; Baril, S. A.; Kannan, A.; Arnold, F. H.; Brustad, E. M. A serine-substituted P450 catalyzes highly efficient carbene transfer to olefins in vivo. Nat. Chem. Bio. 2013, 9, 485487.

(15) Zhang, R. K.; Chen, K.; Huang, X.; Wohlschlager, L.; Renata, H.; Arnold, F. H. Enzymatic assembly of carbon-carbon bonds via ironcatalysed $s p^{3} \mathrm{C}-\mathrm{H}$ functionalization. Nature 2019, 565, 67-72.

(16) See ref 11e for an example of an engineered P411 enzyme constructing a methyl-ethyl stereocenter.

(17) Cui, X.; Xu, X.; Wojtas, L.; Kim, M. M.; Zhang, X. P. Regioselective synthesis of multisubstituted furans via metalloradical cyclization of alkynes with $\alpha$-diazocarbonyls: Construction of functionalized $\alpha$-oligofurans. $J$. Am. Chem. Soc. 2012, 134, 19981-19984.

(18) See refs $10 \mathrm{~d}, 10 \mathrm{~g}$ and 13 for examples of tunable chemoselectivities with engineered hemeproteins.

\section{Table of Contents (TOC)}

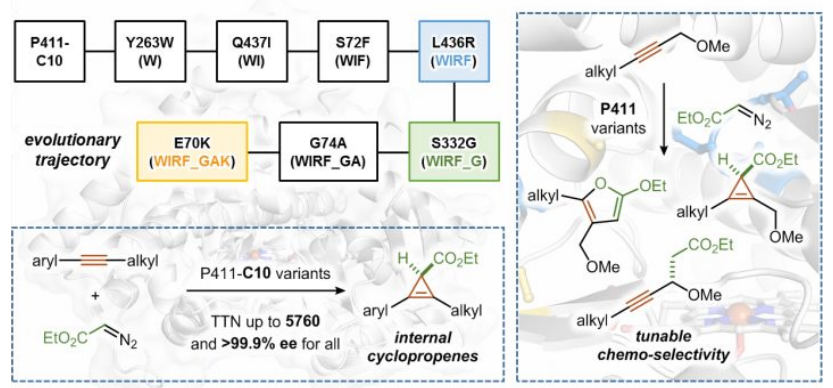




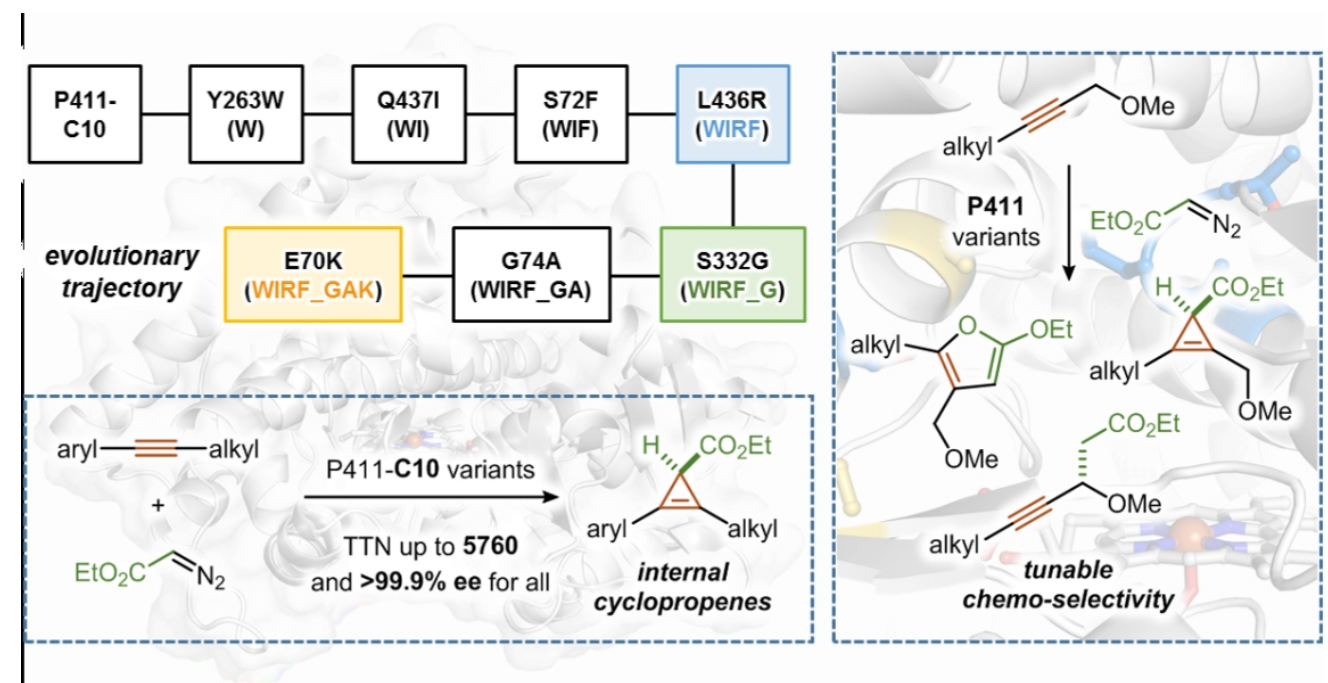

graphic abstract

$206 \times 106 \mathrm{~mm}(150 \times 150 \mathrm{DPI})$ 